IZA DP No. 7363

Altruism and Relational Incentives in the Workplace

Robert Dur

Jan Tichem

April 2013

Forschungsinstitut

zur Zukunft der Arbeit

Institute for the Study

of Labor 


\title{
Altruism and Relational Incentives in the Workplace
}

\author{
Robert Dur \\ Erasmus University Rotterdam, \\ Tinbergen Institute, CESifo and IZA \\ Jan Tichem \\ Erasmus University Rotterdam \\ and Tinbergen Institute
}

Discussion Paper No. 7363

April 2013

IZA
P.O. Box 7240
53072 Bonn
Germany

Phone: +49-228-3894-0

Fax: +49-228-3894-180

E-mail: iza@iza.org

Any opinions expressed here are those of the author(s) and not those of IZA. Research published in this series may include views on policy, but the institute itself takes no institutional policy positions. The IZA research network is committed to the IZA Guiding Principles of Research Integrity.

The Institute for the Study of Labor (IZA) in Bonn is a local and virtual international research center and a place of communication between science, politics and business. IZA is an independent nonprofit organization supported by Deutsche Post Foundation. The center is associated with the University of Bonn and offers a stimulating research environment through its international network, workshops and conferences, data service, project support, research visits and doctoral program. IZA engages in (i) original and internationally competitive research in all fields of labor economics, (ii) development of policy concepts, and (iii) dissemination of research results and concepts to the interested public.

IZA Discussion Papers often represent preliminary work and are circulated to encourage discussion. Citation of such a paper should account for its provisional character. A revised version may be available directly from the author. 
IZA Discussion Paper No. 7363

April 2013

\section{ABSTRACT}

\section{Altruism and Relational Incentives in the Workplace ${ }^{*}$}

This paper studies how altruism between managers and employees affects relational incentive contracts. To this end we develop a simple dynamic principal-agent model where both players may have feelings of altruism or spite toward each other. The con- tract may contain two types of incentives for the agent to work hard: a bonus and a threat of dismissal. We find that altruism undermines the credibility of a threat of dis- missal but strengthens the credibility of a bonus. Among others, these two mechanisms imply that higher altruism sometimes leads to higher bonuses, while lower altruism may increase productivity and players utility in equilibrium.

JEL Classification: D23, J33, M52, M55

Keywords: altruism, spite, incentives, relational contracts, efficiency wages, subjective performance evaluation, Nash bargaining

Corresponding author:

Robert Dur

Department of Economics

Erasmus University Rotterdam

H 9-15

P.O. Box 1738

3000 DR Rotterdam

Netherlands

E-mail: dur@ese.eur.nl

\footnotetext{
* We gratefully acknowledge comments and suggestions by two referees and a co-editor of this journal, Hannes Mueller, Arjan Non, Canice Prendergast, Anja Schöttner, Robin Zoutenbier, Floris Zoutman, and participants to the 2011 CESifo Area Conference on Behavioural Economics in Munich, the 2011 ZEW/Tinbergen Institute Workshop on Behavioural Personnel Economics in Mannheim, the 2012 Workshop on the Social Dimension of Organizations in Budapest, and the 2012 Annual Congress of the European Economic Association in Málaga.
} 


\section{Introduction}

Incentive contracts for workers often do not rely on objective performance measures only. Indeed, "thinking of any job in which subjective evaluation or supervisor discretion does not play some role in incentives is difficult" (Gibbs 2012, p. 15). Subjective performance evaluation sometimes affects pay. For example, $34 \%$ of employees in the industrial sector in the UK received some form of merit pay "which depended on a subjective judgement by a supervisor or manager of the individual's performance" (quoted by MacLeod and Malcomson (1998) from Millward et al. 1992, (p. 388)). ${ }^{1}$ However, the use of subjective performance evaluation is not restricted to bonus pay only. Managers and employees regularly have an understanding that the employment relationship is only continued if performance is satisfactory, which is often a subjective matter. If the job is valuable to a worker, such a threat of dismissal also works as an incentive device (Shapiro and Stiglitz 1984). A prominent example is Henry Ford's five-dollar-day program which almost doubled wages (Raff and Summers 1987). Indirect evidence that many firms use efficiency wages as an incentive device is that bonuses are more common when the unemployment rate is low, that is, when having a job is less valuable to a worker (MacLeod and Parent 2000).

Subjective performance evaluation can overcome some well-known problems related to the use of objective performance measures, such as multi-tasking concerns, measurement costs, and lack of flexibility. When such problems are severe, managers may revert to 'relational contracts' in which employee performance is evaluated subjectively in a holistic way (Gibbons 1998, Prendergast 1999). However, a difficulty with relational contracts is that they cannot

\footnotetext{
${ }^{1}$ See MacLeod and Parent (2000) and Gibbs et al. (2004) for similar evidence concerning subjectively determined bonuses in other sectors.
} 
be enforced in court, but instead must be self-enforcing. Promises and threats contained in a relational contract may therefore be weak as they are constrained by their credibility. In recent decades, a rich theoretical literature has developed studying the optimal design and use of relational contracts (see among others Bull 1987, MacLeod and Malcomson 1989 and 1998, Baker et al. 1994, and Levin 2003).

The present paper contributes to this literature by studying how altruism between managers and employees affects the optimal design of relational contracts. To this end we develop a simple dynamic principal-agent model where both players have some bargaining power. A moral hazard problem exists because both the agent's effort and performance are non-verifiable. For this reason, contracts that condition on effort or performance are not enforceable in court, and must therefore be self-enforcing. The contract may contain two types of incentives for the agent to work hard: a promise to pay a bonus for good performance as in Baker et al. (1994), and a high wage combined with a threat of dismissal following bad performance (efficiency wages) as in Shapiro and Stiglitz (1984). Our key innovation is that we allow both players to have feelings of altruism and/or spite toward each other. These feelings need not be symmetric. Our analysis yields several potentially testable hypotheses as well as a number of management implications.

So far, most studies on relational contracts have abstracted from altruism or spite between the contracting parties. This is somewhat surprising given the prevalence of relational contracts in the workplace, as described above, and the abundance of evidence for the existence of altruism and spite between managers and employees. Surveys among managers reveal that friendships between managers and employees occur frequently (see for instance Berman et al. 2002). Furthermore, Campbell and Kamlani (1997) find that a large ma- 
jority of US compensation managers deem good quality manager-employee relations more important in determining effort than good working conditions, high wages, and monitoring. ${ }^{2}$ There is also evidence for the occurrence of bad manager-employee relationships. Moerbeek and Need (2003) report Dutch data showing that in eight percent of the jobs respondents had in their lives, they got along with their manager badly or very badly. More tentatively, Kahneman et al. (2004) report diary evidence from a US sample of employed women showing that of all regular daily activities, respondents dislike most to interact with their boss. ${ }^{3}$

Some of the results from the present analysis can best be compared against the benchmark of the traditional relational contracts literature, which commonly assumes selfish preferences. In this respect, our first key result is that higher altruism (meaning that either the principal, the agent, or both are more altruistic) improves the credibility of a promise to pay a bonus, ceteris paribus. The reason is twofold. First, higher altruism makes the relational contract more valuable, which gives the principal stronger incentives to adhere to it. Second, an altruistic principal partly internalizes the benefits of the bonus to the agent, which reduces the principal's costs of honoring the contract. The second key result is that higher altruism undermines the credibility of a threat of dismissal. Intuitively, altruism makes the employment relationship more valuable, also if the worker shirks. As a consequence, the principal may find it attractive to retain a worker with whom she has good ties even if the worker shirks, implying that a threat of dismissal is not credible. Practitioners seem to be well-aware of

\footnotetext{
${ }^{2}$ In line with this, an extensive literature in organizational psychology has established a strong positive correlation between the quality of the manager-employee relationship and employee performance (see e.g. Wayne et al. 1997 and Rhoades and Eisenberger 2002).

${ }^{3}$ There is also substantive laboratory evidence indicating that a majority of people are altruistic, even to strangers, see the review by Andreoni et al. (2008). However, other people are actually spiteful. For instance, Andreoni and Miller (2002) find that $55 \%$ of their sample is altruistic while $23 \%$ is spiteful.
} 
the impact of altruism on the credibility of incentives. In line with our first key result, it has been claimed that managers can more credibly make promises if they are "individuals whom others perceive to be [...] likeable - they're pleasant. You enjoy being around them. You may not necessarily want them for your best friend, but you wouldn't mind having a meal or drink with them.". 4 Corroborating our second key result, others have recognized that "to fire a friend is one of the hardest tests of leadership...". ${ }^{5}$

Further, we find that altruism and spite have the following implications for optimal relational contracts. First, in case of strong feelings of spite, players don't contract even though the economic surplus from trading is positive. This holds because feelings of spite imply a social cost from entering into or continuing an employment relationship.

Second, in case of strong feelings of altruism, no incentives are required at all to make the agent work hard. The reason is that an altruistic agent enjoys enriching the principal. Hence, the optimal contract is a flat-wage contract without a threat of dismissal that, nevertheless, results in high effort.

Third, in the presence of moderate feelings of altruism, both incentive types are credible. In that case, the use of both incentives is sometimes necessary to induce high effort. However, it can also happen that players are indifferent between using both incentives or only one of them. The reason is that either the principal's rents may be so large that she can credibly promise a bonus which is sufficiently high to induce high effort, or the job may be so valuable

\footnotetext{
${ }^{4}$ Tony Simons and Liz Guthridge, "How to Help Your Leaders be Credible in Incredible Times." Integrity Dividend LLC, August 1, 2010, accessed April 4, 2013, http://integritydividend.com/leadership/how-tohelp-your-leaders-be-credible-in-incredible-times.html.

${ }^{5}$ Robert Bruner, "To Fire a Friend." The Economic Times, March 16, 2012, accessed March 19, 2013, http://articles.economictimes.indiatimes.com/2012-03-16/news/31201692_1_managers-drinkingfriends-assassination-attempt.
} 
to the agent that a threat of dismissal provides sufficiently strong incentives, or both.

Fourth, for sufficiently high altruism, a threat of dismissal is no longer credible and so the only available incentive is a promise to pay a bonus. The optimal relational contract induces high effort through bonus pay if the discount factor is sufficiently high. If the latter condition is not satisfied, neither a threat of dismissal nor a bonus is credible, but players still enter into an employment relationship. The reason is that, if a threat of dismissal is not credible, it is by definition attractive to hire the agent even if he shirks. Hence, the optimal contract has no incentives and results in low effort.

The remaining results from our analysis can best be compared with the literature that examines how social preferences affect the use of incentives in one-shot games (e.g. Prendergast and Topel 1996, Dur and Glazer 2008, and Lee and Persson 2011). ${ }^{6}$ Starting from the low-effort contract described above, we find the following counterintuitive comparative static results. First, in contrast to received wisdom (Casadesus-Masanell 2004, Sliwka 2007, Shchetinin 2010, and Non 2012), higher altruism can lead to higher bonuses. This follows directly from the first key result that altruism improves the credibility of a bonus. Second, lower altruism can lead to higher effort. This holds because lower altruism may make a threat of dismissal credible, which implies that it becomes possible to induce high effort. As a result, a marginal decrease in altruism can increase players' utility in equilibrium.

Summarizing, the interaction of altruism and relational incentives yields a number of unique insights. First, whether altruism improves the credibility of relational incentives depends crucially on the kind of incentive that is being used. Second, higher altruism may

\footnotetext{
${ }^{6}$ See the working paper version of this paper (Dur and Tichem 2012) for an extensive review of this literature.
} 
lead to higher bonuses. Last, players may benefit from lower altruism when this makes a threat of dismissal credible.

Most closely related to the present analysis is the contribution by Cordero Salas and Roe (2012) who study relational contracting between a selfish agent and an altruistic principal. As in our analysis, the credibility of the bonus increases in the principal's altruism. Our paper differs in that we allow both players to have feelings of altruism and spite. Moreover, as both players have some bargaining power, the relational contract in our model may contain a threat of dismissal. Kragl and Schmid (2009) analyze the impact of inequity aversion between two agents on the credibility of the principal's promise to pay a bonus conditional on individual performance. The authors show that the effect is ambiguous. First, inequity averse agents work harder for a given level of the bonus which strengthens the principal's incentives to stick to her promise. But second, agents demand an inequity premium for accepting the job which makes it more attractive for the principal to renege. The first effect may outweigh the second, implying that agent's inequity aversion can be beneficial to the principal. Our paper differs in a number of important ways. First, our focus is on altruism and spite rather than inequity aversion. Second, the agent's feelings of altruism and spite are directed towards the principal rather than to co-workers, and the principal may be altruistic or spiteful towards the agent as well. Last, in our analysis relational contracts may contain a threat of dismissal besides a possible promise of bonus pay.

Also related to our analysis is Brown et al. (2004) who formally derive, and confirm in the laboratory, the hypothesis that if some unobserved fraction of agents is reciprocal, longterm relational contracts will emerge that generate high effort levels, exhibit rent-sharing, and punish low effort with dismissal. The reason is that principals pay rents in order to 
motivate reciprocal agents which, in turn, gives selfish agents an incentive to mimic reciprocal workers (see also Brown et al. 2012). Our paper differs in that we assume that players are unconditionally altruistic or spiteful, types are observable, and we focus on one principalagent pair. Importantly, we also allow the principal to have feelings of altruism or spite.

The remainder of the paper is structured as follows. The next section describes the model. Section 3 contains the main analysis and results. Section 4 concludes with a discussion of management implications, testable predictions, and directions for further research.

\section{The Model}

We develop a principal-agent model where both players may be altruistic or spiteful toward each other. To focus on the effect of altruism and spite and avoid unnecessary complications, we assume that players are risk-neutral. ${ }^{7}$ The utility of the principal is given by ${ }^{8}$

$$
\Pi=\pi+\gamma U
$$

where $\pi \equiv q(e)-w$ is the principal's profits, $w$ is the agent's compensation, and $q(e)$ is the value of output which is a function of agent's effort $e$. The term $\gamma U$ denotes the altruistic part of the principal's utility where $U$ is the agent's utility and $\gamma$ denotes the degree of the principal's altruism. We call $\gamma$ the principal's altruism parameter. Similarly, the agent's utility is given by

$$
U=u+\alpha \Pi
$$

\footnotetext{
${ }^{7}$ See Casadesus-Masanell (2004) for a study of the interaction between agent's altruism and risk aversion.

${ }^{8}$ Unless otherwise stated, all variables are defined on a per-period basis.
} 
where $u \equiv w-\theta e$ is the agent's private utility, consisting of his compensation minus effort costs. The term $\alpha \Pi$ is the agent's altruistic utility, where $\alpha$ is the agent's altruism parameter. Clearly, an altruism parameter below zero reflects spite.

We assume that players know each other's altruism parameter. Further, we assume that neither player cares for the other's utility as much, or more, as he cares for his own utility; that is, $\alpha, \gamma \in(-1,1)$. The players' utility functions - which are infinite recursions of each other - can therefore be expressed as ${ }^{9}$

$$
\Pi=\frac{1}{1-\alpha \gamma}(\pi+\gamma u), \quad \text { and } \quad U=\frac{1}{1-\alpha \gamma}(u+\alpha \pi) .
$$

In each period that the agent is employed, he can exert low effort or high effort, denoted by $e \in\{0,1\}$. Low effort results in low value of output, $q=L$, while high effort yields high value of output, $q=H$. The costs of exerting high effort to the agent are $\theta$ while exerting low effort is, for reasons of convenience but without loss of generality, assumed to be not costly. To make the problem interesting, we assume $H-\theta>L>0$ and $H-\theta>\bar{\Pi}+\bar{U}$, where $\bar{\Pi}>0$ and $\bar{U}>0$ are the principal's and the agent's outside options, respectively. $\bar{\Pi}$ and $\bar{U}$ are independent of player's type, which has two implications. First, the pair $(\alpha, \gamma)$ is specific to this relationship and thus does not reflect players' general altruistic or spiteful attitudes. Second, feelings of altruism or spite vanish if the players do not contract with each other (anymore). Lastly, note that $\bar{\Pi}$ and $\bar{U}$ can be interpreted as including the expected altruism or spite that would result when being matched to some other player.

\footnotetext{
${ }^{9}$ For a thorough exposition of when interdependent utility functions form a unique system and can be defined on underlying utility drivers instead of some person's utility, see Bergstrom (1999).
} 
The second important ingredient of the model is that both effort and output can only be assessed subjectively, and hence contracts that condition on effort or output are not enforceable in court. Any contract that includes compensation or punishment that is conditional on effort or output must therefore be self-enforcing. This can only hold in a repeated interaction setting. The model therefore includes an infinite number of periods, where players discount utility from future periods by a constant common factor $\delta$. The self-enforceability of relational contracts depends further on the punishments inflicted upon the principal when she does not keep a promise or carry out a threat when the contract prescribes her to do so. Many models assume that the agent plays a trigger strategy that prescribes to break off trade when the principal reneges (e.g. Bull 1987, MacLeod and Malcomson 1989 and 1998, and Levin 2003). Following Baker et al. (1994), we do not impose that the agent always leaves the firm after contract breach. Instead we assume that after contract breach the agent will never believe any promise or threat in the future anymore. ${ }^{10}$ Note that because this is a dynamic game of complete information, we solve for the subgame perfect equilibrium of the game.

The order of the game within a period is as follows. First, the principal chooses whether or not to hire the agent. Second, if the agent is hired, the players bargain over a contract which may contain a contractible base salary $(s)$, a promise to pay a bonus $(b)$ in case of high output, and a threat of dismissal in case of low output. ${ }^{11}$ The outcome of contract

\footnotetext{
${ }^{10}$ One could argue that, if the principal employs more than one agent, she could overcome a possible credibility problem by using a tournament (see e.g. Carmichael 1983). While this may resolve the principal's problem of credibly committing to pay a bonus, multiple agents introduce a new credibility problem in the assignment of the bonus. That is, the principal will be tempted to award prizes to the agents she likes most rather than to the best-performing agents.

${ }^{11}$ Throughout the paper, we abstract from the use of severance pay (or bonds). Severance pay leaves the credibility of bonus pay unaffected (MacLeod and Malcomson 1989). However, negative severance pay (that is, contracting on a transfer from the agent to the principal in case the principal dismisses the agent) can be
} 
negotiations is assumed to be given by the generalized Nash bargaining solution. We assume bargaining in order to create an environment in which it can be optimal to use a threat of dismissal as an incentive device. This is never the case if the principal holds all the bargaining power, since a threat of dismissal is only effective if the agent is paid costly rents (see MacLeod and Malcomson 1989). Assuming Nash bargaining thus enables us to study the impact of altruism and spite on the use of a threat of dismissal. ${ }^{12}$ Third, if a contract is agreed upon, the agent chooses an effort level. Fourth, output is realized and observed by both players. The principal decides whether or not to pay the bonus, and payoffs are realized. After that, a new period starts. By not rehiring the agent in this new period, the principal can exercise a threat of dismissal.

Typically, repeated games have many non-stationary equilibria. As is usual in the literature, we focus on stationary equilibria, that is, the principal and agent agree to the same contract every period. ${ }^{13}$ Also, we assume that the contract only contains a particular type of incentive if necessary and credible.

used to make a threat of dismissal credible.

${ }^{12}$ The generalized Nash bargaining solution rests on three axioms: invariance, efficiency, and independence of irrelevant alternatives. The generalized Nash bargaining solution is a cooperative solution concept in the sense that players cooperate in dividing a given surplus from the labor relationship between each other. However, generalized Nash bargaining does not overcome the central commitment issues studied in this paper, namely the credibility of bonus pay and a threat of dismissal. Credibility of incentives may only exist by virtue of the agent's trigger strategy and repeated play. For an extensive discussion on how bargaining affects relational contracts, see Cordero Salas (2011).

${ }^{13}$ By Levin (2003)'s argument, stationary contracts can provide the agent with the same incentives as non-stationary compensation plans. This holds because in this model future rents and a bonus are perfect substitutes. Also note that the credibility of the bonus is unaffected by the choice whether to use future rents or a bonus (see MacLeod and Malcomson 1989). Finally, the credibility of a threat of dismissal is independent of the issue of (non-)stationarity, as will become clear in the next section. Hence, any complex non-stationary compensation plan can be replicated by a simple stationary one, maintaining the agent's incentives and the credibility of the contract. 


\section{Analysis}

We start our analysis by deriving the conditions for the credibility of incentives. Next, we study under what conditions the agent exerts high effort. The section concludes with characterizing the optimal relational contract for any pair $(\alpha, \gamma)$.

\subsection{Credibility of Incentives}

Before we can derive the credibility of relational incentives, we need to derive the value of the relational contract to the principal. The value of the relational contract to the principal depends, among others, on the outcome of the contract negotiations between her and the agent. Recall that we assume that the outcome of the negotiations is given by generalized Nash bargaining, which states that the agent's total compensation $w$ is the solution to:

$$
\max _{w} \Phi \equiv[\Pi(w)-\bar{\Pi}]^{1-\beta_{A}}[U(w)-\bar{U}]^{\beta_{A}}
$$

subject to the players' participation constraints

$$
\Pi(w)-\bar{\Pi} \geq 0 \text { and } U(w)-\bar{U} \geq 0
$$

If the players fail to reach an agreement, then they receive their outside option utilities. The agent's bargaining power is represented by $0<\beta_{A}<1$. Note that in the extreme case where $\beta_{A}=0$, the principal has the power to make the agent a take-it-or-leave-it offer. 
Solving (1) yields the agent's total compensation level given his effort choice:

$$
w^{*}(e)=\frac{1}{1-\alpha}[(1-\alpha \gamma) \bar{U}+\theta e-\alpha q(e)]+\beta_{A} \frac{1-\alpha \gamma}{(1-\alpha)(1-\gamma)} S(e),
$$

where $S(e) \equiv q(e)-\theta e-(1-\gamma) \bar{U}-(1-\alpha) \bar{\Pi}$ measures the surplus of the relationship. It is easy to verify that for any $\beta_{A}>0$ and $S(e)>0$ the agent earns a rent from the job. Also, the agent's compensation and thereby his utility, are increasing in the agent's bargaining power $\beta_{A}$, as in Cordero Salas (2011). Next, it can be shown that altruism gives rise to compensating wage differentials, as in Grund and Sliwka (2005), Delfgaauw and Dur (2007), and Arce (2010). However, the sign of these depend on the agent's bargaining power. ${ }^{14}$

Given that the agent's compensation equals $w^{*}(e)$, both players' participation constraints reduce to

$$
S(e) \equiv q(e)-\theta e-(1-\gamma) \bar{U}-(1-\alpha) \bar{\Pi} \geq 0 . \quad \quad\left(\mathrm{PC}_{P}, \mathrm{PC}_{A}\right)
$$

The reason for why the players' participation constraints are identical is that players divide the surplus of the contract proportional to their bargaining power. Hence, all that matters

\footnotetext{
${ }^{14}$ Derivating $w^{*}(e)$ to $\alpha$ and $\gamma$ yields:

$$
\begin{aligned}
& \frac{\partial w^{*}(e)}{\partial \alpha}=-\left(1-\beta_{A}\right) \frac{1}{(1-\alpha)^{2}}[q(e)-\theta e-(1-\gamma) \bar{U}]+\beta_{A} \frac{\gamma}{1-\gamma} \bar{\Pi} \gtreqless 0 \text { and } \\
& \frac{\partial w^{*}(e)}{\partial \gamma}=-\left(1-\beta_{A}\right) \frac{\alpha}{1-\alpha} \bar{U}+\beta_{A} \frac{1}{(1-\gamma)^{2}}[q(e)-\theta e-(1-\alpha) \bar{\Pi}] \gtreqless 0 .
\end{aligned}
$$

Note that in the extreme case where the agent has no bargaining power at all, it holds that $\frac{\partial w^{*}(e)}{\partial \alpha}<0$. The intuition is that the principal extracts all of the agent's altruistic utility by decreasing his compensation. In the other extreme where $\beta_{A}=1$, it is the agent who extracts all rents from the relationship. Whether the agent can extract more utility from the principal if he becomes more altruistic then depends on the principal's feelings. If the principal is spiteful, she dislikes working with a more altruistic agent (simply because the agent enjoys more utility when more altruistic) and so she must be compensated; hence $w^{*}(e)$ decreases in $\alpha$ if $\beta_{A}=1$ and $\gamma<0$. On the other hand, if the principal is altruistic, she enjoys employing a more altruistic agent and so $w^{*}(e)$ increases in $\alpha$ if $\beta_{A}=1$ and $\gamma>0$. A similar but reverse intuition can be provided for the impact of the principal's altruism on the agent's compensation.
} 
for participation is whether the relationship yields a non-negative surplus. Also note that because both players have some bargaining power, each player's utility is increasing in $S(e)$. We are now ready to derive the credibility of relational incentives.

A threat of dismissal is only credible when the principal is willing to fire the agent if he is caught shirking. Recall that if a contract contains a threat of dismissal and the agent is nevertheless retained after shirking, he will never believe a threat or promise in the future anymore. Hence, if the agent is retained after he is caught shirking, the agent will forever shirk. Therefore, a threat of dismissal is credible only if the principal is better off dismissing the agent rather than retaining the agent knowing that he will shirk, $\bar{\Pi} \geq \Pi\left(w^{*}, e=0\right)$. This condition is the reverse of the participation constraint with $e=0$ :

$$
S(e=0) \equiv L-(1-\gamma) \bar{U}-(1-\alpha) \bar{\Pi} \leq 0 .
$$

The above condition reveals that the surplus from the low-effort contract is increasing both in the principal's and the agent's altruism. The intuition is that altruism entails a social benefit from working together. Hence, the principal is not willing to fire the agent if altruism is sufficiently high. This is our first key result.

Proposition 1 If $\alpha \geq 1-\frac{1}{\bar{\Pi}}[L-(1-\gamma) \bar{U}$, then a threat of dismissal is not credible.

The other non-contractible part of the contract is a promise to pay a bonus for high output. For the bonus to be credible, it must be in the principal's interest to pay it conditional on observing high output. Adhering implies that the principal must incur bonus costs in the present, but she retains the opportunity to implement credible incentives in the future. 
Assuming a threat of dismissal is credible, one can derive that a bonus is credible if:

$$
\frac{\delta}{1-\delta}[\Pi(s, b, e=1)-\bar{\Pi}]-\frac{1-\gamma}{1-\alpha \gamma} b \geq 0 .
$$

Similarly, if the principal prefers to retain the agent after contract breach $(S(e=0)>0)$, credibility of the bonus $\left(\mathrm{CC}_{B}^{\prime}\right)$ is guaranteed if

$$
\frac{\delta}{1-\delta}\left[\Pi(s, b, e=1)-\Pi\left(w^{*}, e=0\right)\right]-\frac{1-\gamma}{1-\alpha \gamma} b \geq 0 .
$$

The credibility constraints essentially state that paying a bonus is only credible when doing so yields sufficient rents in the future. Therefore, the credibility of a bonus increases in the principal's discount factor $\delta$. Further, it can be easily derived that the credibility of the bonus increases in the agent's altruism. Assuming a threat of dismissal is credible, and the agent earns total compensation equal to $w^{*}(e=1)$ as is shown to be always the case in the next subsection, one can derive:

$$
\frac{\partial \mathrm{CC}_{B}}{\partial \alpha}=\frac{\delta\left(1-\beta_{A}\right)}{1-\delta} \frac{1}{(1-\alpha)^{2}}\left[H-\theta-(1-\gamma) \bar{U}+\frac{(1-\alpha)^{2} \gamma}{1-\gamma} \bar{\Pi}\right]>0
$$

where $\mathrm{CC}_{B}$ denotes the left-hand side of $\left(\mathrm{CC}_{B}\right)$, and the sign follows if participation is ensured. The intuition is the same as the one behind Proposition 1. If the agent is more altruistic the surplus of the relationship increases. Some of the increase of the surplus accrues to the principal depending on his bargaining power. It follows that it is more valuable for the principal to uphold the relational contract with the agent. The credibility of the bonus 
also increases in the principal's altruism:

$$
\frac{\partial \mathrm{CC}_{B}}{\partial \gamma}=\frac{\delta\left(1-\beta_{A}\right)}{1-\delta} \frac{1}{(1-\gamma)^{2}}\left[H-\theta+\frac{(1-\gamma)^{2} \alpha}{1-\alpha} \bar{U}-(1-\alpha) \bar{\Pi}\right]>0
$$

The reason is that, as above, an increase in the principal's altruism increases the principal's rents from the relationship. In addition, a more altruistic principal experiences lower costs of paying a bonus, as she internalizes part of the benefit of the bonus to the agent. The same results hold if a threat of dismissal is not credible. ${ }^{15}$ Hence, our second key result is:

Proposition 2 Let $\bar{b}$ denote the maximum level of the bonus that the principal can credibly promise. It holds that $\bar{b}$ is strictly increasing in $\alpha$ and $\gamma\left(\frac{\partial \bar{b}}{\partial \alpha}>0\right.$ and $\left.\frac{\partial \bar{b}}{\partial \gamma}>0\right)$.

\subsection{The Optimal Relational Contract}

Next consider the agent's incentive compatibility constraint. The agent is only willing to exert high effort if doing so yields higher expected lifetime utility than shirking does. Let's first suppose the contract contains a credible threat of dismissal. The incentive compatibility

${ }^{15}$ Derivating the left-hand side of $\mathrm{CC}_{B}^{\prime}$ yields:

$$
\begin{aligned}
\frac{\partial \mathrm{CC}_{B}^{\prime}}{\partial \alpha} & =\frac{\delta\left(1-\beta_{A}\right)}{1-\delta} \frac{1}{(1-\alpha)^{2}}(H-\theta-L)>0, \text { and } \\
\frac{\partial \mathrm{CC}_{B}^{\prime}}{\partial \gamma} & =\frac{\delta\left(1-\beta_{A}\right)}{1-\delta} \frac{1}{(1-\gamma)^{2}}(H-\theta-L)>0 .
\end{aligned}
$$

The intuition behind these comparative static results is slightly different from the one in the main text. The reason is that the principal's utility from reneging is not her outside option utility, but the utility from the low-effort contract. It always holds that the principal's utility from a contract increases in both players' altruism. However, the principal's utility rises faster with altruism under the high-effort contract compared to the low-effort contract. Therefore, higher altruism makes it more attractive to the principal to adhere to the bonus also if a threat of dismissal is not credible. 
constraint is then given by:

$$
\frac{1-\alpha}{1-\alpha \gamma} b+\frac{\delta}{1-\delta}[U(s, b, e=1)-\bar{U}]+\frac{\alpha}{1-\alpha \gamma}(H-L) \geq \frac{1}{1-\alpha \gamma} \theta .
$$

The right-hand side denotes the agent's costs of exerting high effort. The left-hand side describes the benefits from exerting high effort which may be threefold: a bonus, a stream of future rents, and intrinsic joy of enriching the principal arising from the agent's altruism. Assuming that the agent's compensation equals $s+b=w^{*}(e=1)$ as described by (2) (which we prove always to be the case in the proof of Proposition 4), the minimum required bonus to induce high effort can be written as:

$$
b^{*}=\frac{1}{1-\alpha}\left[\theta-\alpha(H-L)-\frac{\delta \beta_{A}}{1-\delta} \frac{1-\alpha \gamma}{1-\gamma} S(e=1)\right],
$$

where $S(e=1)$ is described by $\left(\mathrm{PC}_{P}, \mathrm{PC}_{A}\right)$ with $q(e)=H$ and $e=1$. It is easy to verify that the minimum required bonus $b^{*}$ is decreasing in both players' altruism. The reason is twofold. First, a more altruistic agent experiences more altruistic utility from enriching the principal. Second, as derived in the previous sub-section, the contract becomes more valuable to the agent if either player becomes more altruistic. Hence, provided that the contract contains a credible threat of dismissal, a lower bonus is required.

Next suppose that a threat of dismissal is not credible and, hence, is not part of the contract. Then, the agent's effort choice does not affect his future employment status. The reason is that the principal will retain the agent in any case. Consequently, the agent only takes the current costs and benefits of effort into account and exerts high effort if the bonus 
equals at least:

$$
b^{* *}=\frac{1}{1-\alpha}[\theta-\alpha(H-L)]
$$

This expression reveals that for sufficiently high agent's altruism, incentives are unnecessary to induce high effort. This is the case when $\alpha \geq \frac{\theta}{H-L}$. It follows directly that the optimal relational contract in this case is simply a flat wage contract without threat of dismissal. By generalized Nash bargaining, the agent's total compensation equals $w^{*}(e=1)$ as described by (2). Our next Proposition follows.

Proposition 3 Sufficiently altruistic agents $\left(\alpha \geq \frac{\theta}{H-L}\right)$ exert high effort even in the absence of incentives. In this case, the optimal contract is a contract without incentives that results in high effort. The agent's total compensation equals $s=w^{*}(e=1)$ as described by (2).

Next we derive the optimal relational contract assuming that the agent needs incentives to exert high effort. The results are given in Proposition 4 and derived and explained in detail in the proof.

Proposition 4 If the agent needs incentives to exert high effort $\left(\alpha<\frac{\theta}{H-L}\right)$, the optimal relational contract is described by the following Table:

\begin{tabular}{|l|c|c|}
\hline & ToD credible & ToD not credible \\
\hline \hline Bonus credible & b) ToD, flat wage, $e=1$ & No ToD, $b \geq b^{* *}, e=1$ \\
& c) no ToD, $b \geq b^{* *}, e=1$ & \\
Bonus not credible & No contract & No incentives, $e=0$ \\
\hline
\end{tabular}


where ToD denotes threat of dismissal. Cases (b) and (c) may apply in addition to case (a) only if respectively the agent's and the principal's future rents are sufficiently large (see condition (3) and (4) below). Further, the agent's total compensation always equals $s+b=$ $w^{*}(e)$ as described by (2).

Proof. First, in the case where neither credibility constraint binds, both types of incentives are credible and so the contract can always induce high effort. By generalized Nash bargaining the agent's compensation is given by $s+b=w^{*}(e=1)$ as described by (2) which yields the agent a rent. Given that the agent earns a rent, any bonus $b \geq b^{*}$ as described by (IC) combined with a threat of dismissal ensures high effort (Case (a)). However, there are potentially two alternatives, depending on the size of the players' rents. If the value of the agent's future rents is sufficiently high, then a threat of dismissal alone can induce high effort (Case (b)). This holds when:

$$
\frac{\delta}{1-\delta}\left[U\left(w^{*}, e=1\right)-\bar{U}\right] \geq \frac{1}{1-\alpha \gamma}[\theta-\alpha(H-L)]
$$

If the value of the principal's future rents is sufficiently high, a bonus contract with $b \geq b^{* *}$ and no threat of dismissal can also induce high effort (Case (c)). This holds when:

$$
\frac{\delta}{1-\delta}\left[\Pi\left(w^{*}, e=1\right)-\bar{\Pi}\right] \geq \frac{1-\gamma}{(1-\alpha \gamma)(1-\alpha)}[\theta-\alpha(H-L)]
$$

Hence, if either condition (3) or (4) holds, the players have various contract types at their disposal to induce high effort. It is easy to verify that both conditions hold for the same values of $\alpha$ and $\gamma$ if $\beta_{A}=\frac{1}{2}$. However, if $\beta_{A}<\frac{1}{2}$ condition (4) binds for lower values of $\alpha$ 
and $\gamma$, whereas otherwise condition (3) binds for lower values of $\alpha$ and $\gamma$.

Second, consider the case where promising a bonus is credible while threatening with dismissal is not. Then, it is still possible to contract on high effort because the required bonus can be credibly promised. By Nash bargaining, the agent's compensation is given by $s+b=w^{*}(e=1)$, where it must hold that $b \geq b^{* *}$ as described by (IC').

Third, if neither incentive is credible, then it is not possible to induce high effort. However, if the threat of dismissal is not credible, it is by definition attractive to hire the agent even if he shirks. The agent is paid compensation resulting from generalized Nash bargaining, $s=w^{*}(e=0)$ as described by (2). Hence, a flat wage contract without threat of dismissal is agreed to when neither incentive is credible.

The final case is where a threat of dismissal is credible but the minimum required bonus, $b^{*}$, is not. Since the threat of dismissal is credible, it is by definition not attractive to contract on low effort. An argument similar to that of MacLeod and Malcomson (1989) proves that the principal does not find it attractive to contract on high effort either, and so no contract is agreed to at all. The argument runs as follows.

The credibility constraint for bonus pay, given that the threat of dismissal is credible, can be rewritten as

$$
b \leq \bar{b} \equiv \delta\left(\frac{1}{1-\gamma}(H-\gamma \theta)-\frac{1-\alpha \gamma}{1-\gamma} \bar{\Pi}-s\right)
$$

where $\bar{b}$ is the maximum credible bonus. Since $\bar{b}<b^{*}$, the maximum credible bonus $\bar{b}$ is too low to satisfy the incentive compatibility constraint (IC). The only way to satisfy (IC) then is to increase the agent's rents by raising the agent's total compensation above $w^{*}(e=1)$. 
Even though this will result in a division of rents that is different from the division implied by the generalized Nash bargaining solution, it may still make the principal better off compared to the case where no contract is agreed to. However, the following argument shows that this is not the case. First note that the impact of increasing the base salary on the incentive compatibility constraint (IC) is zero if $\left(\mathrm{CC}_{B}\right)$ is met with equality:

$$
\frac{\partial \mathrm{IC}}{\partial s}=\frac{1-\alpha}{1-\alpha \gamma} \frac{\partial \bar{b}}{\partial s}+\frac{\delta}{1-\delta} \frac{1-\alpha}{1-\alpha \gamma}\left(1+\frac{\partial \bar{b}}{\partial s}\right)=0,
$$

where, following $\left(\mathrm{CC}_{B}\right), \partial \bar{b} / \partial s=-\delta$. The reason is that increasing the base salary makes the contract less profitable to the principal, and hence the maximum credible bonus decreases. Therefore net incentives from raising the base salary do not change until the maximum credible bonus equals zero. Further, if the principal can only credibly promise a bonus that is equal to zero, it must hold that she earns no rent from the contract, $\Pi(s, b=0, e=1)=\bar{\Pi}$. Moreover, the principal must still increase the base salary in order to satisfy the incentive compatibility constraint (IC). But this violates the principal's participation constraint and so she will not enter into a high-effort contract.

\subsection{Altruism and Contract Selection}

So far we have found that players may agree to different types of relational contracts. In this subsection we investigate what type of contract is selected for any pair $(\alpha, \gamma)$. Naturally there are many different contract mappings, depending on the exact parameterization of the model. However, there is one important qualitative distinction between the different mappings: either higher altruism always increases the surplus from the relationship, or it 


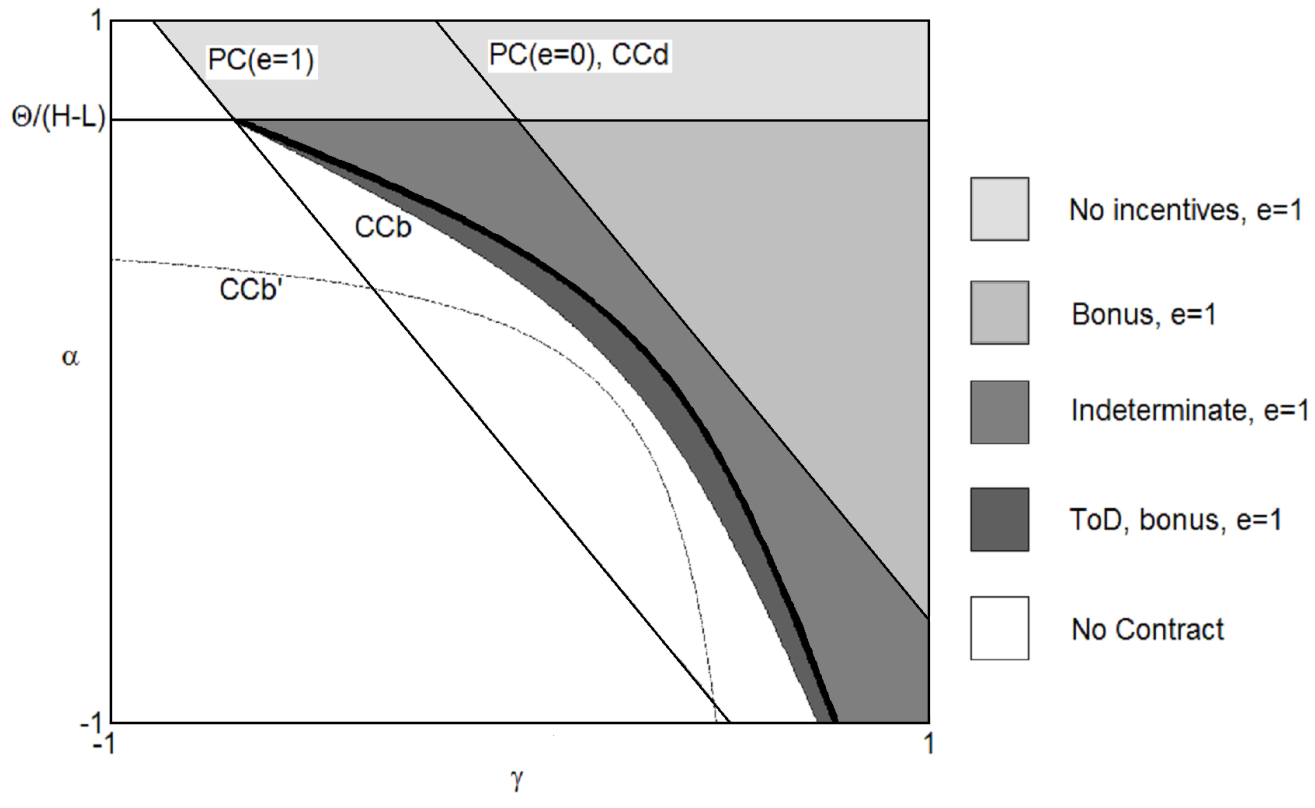

Figure 1: Contract selection as a function of $\alpha$ and $\gamma . H=2.1, L=1, \theta=0.7, \bar{U}=0.58$, $\bar{\Pi}=0.41, \beta_{A}=0.3$, and $\delta=0.75$.

may reduce it sometimes. We start with illustrating the first case in Figure 1, which has the following properties.

First, altruism must be sufficiently high to satisfy the players' participation constraints. Naturally, $\mathrm{PC}(e=0)$ lies to the right of $\mathrm{PC}(e=1)$ as output is lower in the low-effort contract.

Second, high effort is only sustainable if neither player wants to deviate from a higheffort contract. Above the line $\alpha=\frac{\theta}{H-L}$ the agent has sufficiently high altruism to exert high effort without incentives. Hence, above this line the optimal contract is a contract without incentives that results in high output (Proposition 3). Below the line $\alpha=\frac{\theta}{H-L}$, incentives are required to induce high effort, which must be credible. $\mathrm{PC}(e=0)$ demarcates whether the principal finds it attractive to hire the agent if he shirks. Therefore to the right of $\mathrm{PC}(e=0)$ altruism is too high to make credible use of a threat of dismissal (Proposition 
1). Next, depending on the credibility of a threat of dismissal, the principal must promise the agent a bonus equal to at least $b^{*}$ or $b^{* *}$ to induce high effort. Hence, if a threat of dismissal is credible, the credibility constraint for bonus pay becomes

$$
\frac{\delta}{1-\delta}\left[\Pi\left(w^{*}, e=1\right)-\bar{\Pi}\right]-\frac{1-\gamma}{1-\alpha \gamma} b^{*} \geq 0,
$$

whereas otherwise it is

$$
\frac{\delta}{1-\delta}\left[\Pi\left(w^{*}, e=1\right)-\Pi\left(w^{*}, e=0\right)\right]-\frac{1-\gamma}{1-\alpha \gamma} b^{* *} \geq 0 .
$$

The reason that $\mathrm{CC}_{B}$ and $\mathrm{CC}_{B}^{\prime}$ are evaluated at $b^{*}$ and $b^{* *}$ is that players can always lower the bonus to this level, without changing total compensation, which would be optimal if a higher bonus is not credible. ${ }^{16}$ Hence the constraints denote when promising some bonus that induces high effort is feasible. Also note that whenever the agent needs incentives to exert high effort, $\mathrm{CC}_{B}$ lies strictly to the right of $\mathrm{PC}(e=1)$. The reason is that the principal requires a rent to be able to credibly promise a bonus.

Third, at $\mathrm{CC}_{B}$ the relationship is exactly that valuable such that the principal can promise the bonus $b^{*}$ which, in combination with a threat of dismissal, induces high effort from the agent (Proposition 4, case a). As we move to the north-east, altruism becomes higher, and so both players' rents increase. Therefore, at some point it holds that either the principal's or the agent's rents are equal to the agent's costs of effort. This point is determined by either equation (3) or (4) and graphically represented by the fat line. If the agent's rents equal his

\footnotetext{
${ }^{16}$ It can also be easily checked that promising $b^{*}$ and $b^{* *}$ becomes more credible if altruism becomes higher.
} 
cost of effort, an efficiency wage contract without bonus pay induces high effort (Proposition 4, case b). Alternatively, if the principal earns sufficiently high rents, she can credibly promise a bonus that alone induces high effort (Proposition 4, case c). As it is also possible to use both tools instead of only one, several contract types are optimal beyond the fat line till $\mathrm{CC}_{D}$. The model's predictions concerning contract type are therefore indeterminate in this region. ${ }^{17}$

Fourth, anywhere beyond $\mathrm{CC}_{D}$, a threat of dismissal is not credible, but the bonus $b^{* *}$ is credible and so the optimal contract is a bonus contract that induces high effort. However, for different parameterizations, $b^{* *}$ may not always be credible beyond $\mathrm{CC}_{D}$ as we will see in Figure 2.

Figure 2 again represents the mapping from $(\alpha, \gamma)$ pairs to contract type, but now for a lower value of the discount rate. This shifts the bonus credibility constraints to the right as higher altruism is required to make the bonus credible. The crucial difference between Figures 1 and 2 is that there is now an intermediate region where neither incentive is credible. ${ }^{18}$ By Proposition 4, players then agree to a contract without incentives that results in low effort.

To understand why the principal loses the possibility to promise a bonus for some pairs $(\alpha, \gamma)$ beyond $\mathrm{CC}_{D}$, consider the following. If a threat of dismissal is no longer credible, this reinforces the credibility problem concerning the bonus. The reason is twofold. First, the principal's fallback utility from reneging is no longer her outside option utility but her utility from a low-effort contract. By definition the latter is weakly higher than the former if a threat of dismissal is not credible, and so the principal has weaker incentives to stick to

\footnotetext{
${ }^{17}$ In Figure 1 (and Figure 2) the fat line represents equation (4). So, directly to the right of the fat line players can choose to only use a bonus.

${ }^{18}$ Such a region also emerges for a sufficiently high value of the agent's bargaining power $\left(\beta_{A}\right)$.
} 


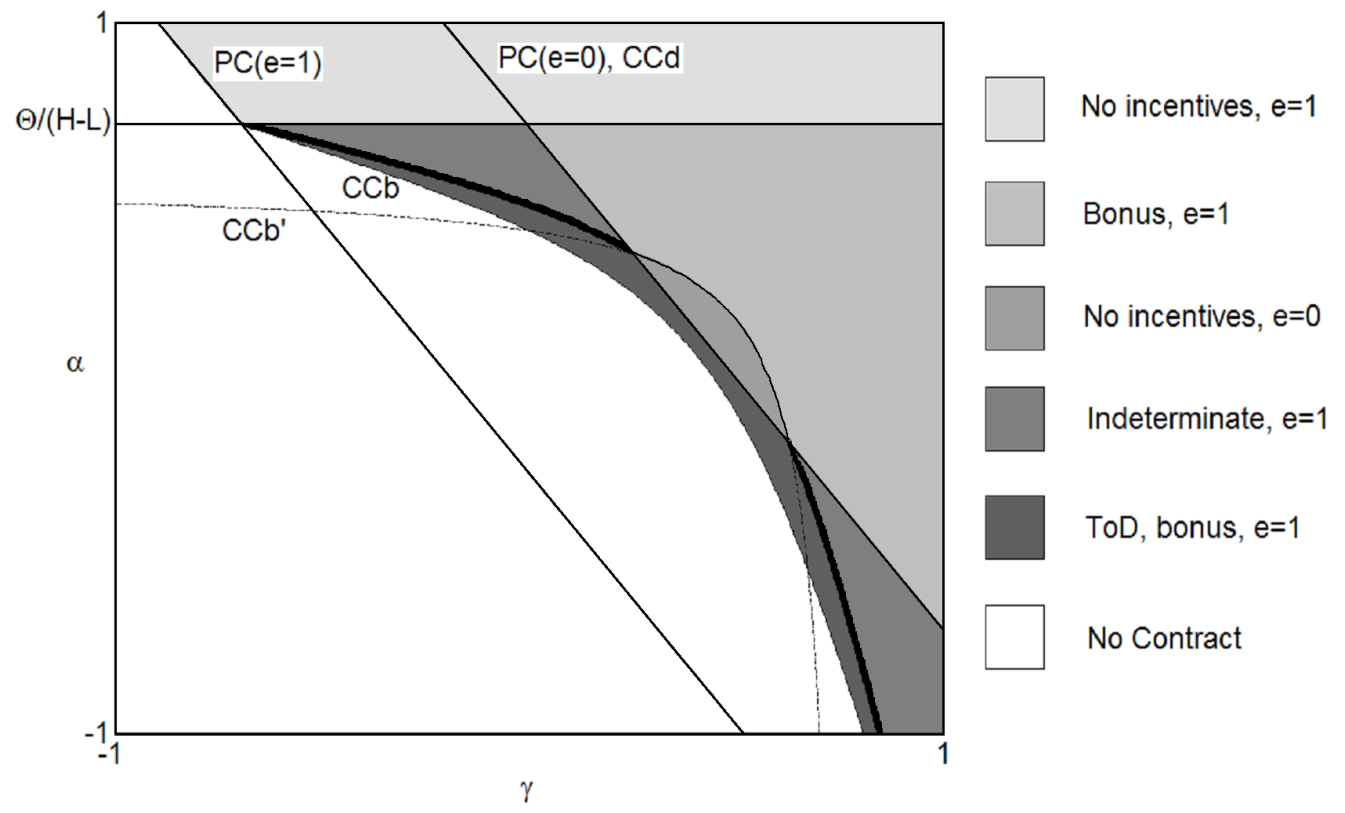

Figure 2: Contract selection as a function of $\alpha$ and $\gamma$. Same parameterization as in Figure 1 , except $\delta=0.6$.

her promise to pay a bonus. Second, if a threat of dismissal is not credible, the agent's rents cannot be used as an incentive device and so the minimum bonus must increase from $b^{*}$ to $b^{* *}$. This again gives the principal stronger incentives to withhold the bonus. For high values of $\delta$ it is never a problem that the bonus must increase from $b^{*}$ to $b^{* *}$ because the present value of adhering to the principal is still large enough, as in Figure 1. However, for low values of $\delta$ the principal's present value of adhering is low, and so a discrete increase in the bonus has a relatively large impact on the credibility constraint. Hence the non-credibility of a threat of dismissal may put too much strain on the promise to pay a bonus.

The optimality of a low-effort contract for intermediate levels of altruism implies two counterintuitive comparative static results. First, at the credibility constraint of a threat of dismissal, a marginal improvement in altruism is harmful to productivity and players' utility in equilibrium. The reason is that, at $\mathrm{CC}_{D}$, a marginal increase in altruism renders a threat 
of dismissal non-credible, and hence, players lose the opportunity to credibly contract upon high effort. Second, at the credibility constraint for bonus pay $\left(\mathrm{CC}_{B}^{\prime}\right)$, a marginal increase in altruism does not lead to lower bonuses as commonly found in the literature (CasadesusMasanell 2004, Sliwka 2007, Shchetinin 2010, and Non 2012), but rather higher. The reason is that higher altruism enables credible use of a bonus. We summarize these results in our final Proposition.

Proposition 5 Depending on the parameterization of the model, a region may exist where players agree on a low-effort contract without incentives. Starting from this low-effort contract, it may hold that for lower values of $\alpha$ and/or $\gamma$, effort and players' utility are strictly higher, while higher values of $\alpha$ and/or $\gamma$ can lead to strictly higher bonuses.

\section{Practical and Testable Implications}

The theoretical analysis conducted above yields a number of clear implications for management. First, we have shown that the credibility of relational incentives depends on the altruism or spite between a manager and employee. Altruism reinforces the credibility of bonus pay whereas it undermines the credibility of a threat of dismissal. Our model therefore suggests that firms in which relationships between management and employees are characterized by altruism benefit more from using bonus pay compared to efficiency wages. Further, when actively shaping organizational culture, firms should be aware that altruism does not necessarily improve the credibility of incentive schemes. This is only the case if incentive schemes rely sufficiently on promises rather than threats.

The second insight is that moderate altruism may lead to inefficiently low effort levels by 
employees. This is the case when altruism is too high to credibly threaten employees with dismissal, but too low to credibly promise a bonus. In response to such a situation, firms can raise productivity by either stimulating or suppressing altruism. The reason is that doing the former makes bonus pay more credible, whereas the latter renders a threat of dismissal more credible.

Third, the presence of altruism increases employees' willingness to work for the firm in the first place. Therefore, altruism between management and employees not only affects employee motivation as described above, but also determines the total compensation level employees require to be willing to work for the firm (see also Grund and Sliwka 2005, Delfgaauw and Dur 2007, and Arce 2010).

The model's predictions can be tested using laboratory experiments and field data. In laboratory experiments, the researcher has the freedom to fine-tune the profitability of the various types of contracts, which is hard outside the lab. Moreover, in contrast to the field, one can easily observe when players decide not to enter into a contract. A bottleneck may be to bring feelings of altruism and, particularly, feelings of spite into the lab. This difficulty may be resolved by recruiting subject pools in which these feelings are already present. One could think of members of (non-)rivalrous sports clubs or student associations. Using field data, one can test whether there is a relationship between contract types and the degree of altruism between manager and employee.

There are avenues for future theoretical research as well. First, it would be interesting to endogenize feelings of altruism. Dur (2009), Englmaier and Leider (2012), and Non (2012) have taken some steps in this direction in one-shot games. Second, it is worth studying how our results change when performance evaluations are done by a potentially altruistic 
middle-manager who is not residual claimant. In one-shot games, this case has been studied by Prendergast and Topel (1996), Lee and Persson (2011), Giebe and Gürtler (2012), and Grund and Przemeck (2012). Tichem (2013) studies this case in a dynamic setting, such as ours.

\section{References}

[1] Andreoni, J. and J. Miller (2002), "Giving according to GARP: An Experimental Test of the Consistency of Preferences for Altruism." Econometrica, 70(2): 737-753.

[2] Andreoni, J., W.T. Harbaugh and L. Vesterlund (2008), "Altruism in Experiments." In The New Palgrave Dictionary of Economics Online, edited by Steven N. Durlauf and Lawrence E. Blume. Palgrave Macmillan.

[3] Arce, D.G. (2010), "Agency and Social Preferences." Mimeo, University of Texas at Dallas.

[4] Baker, G., R. Gibbons and K.J. Murphy (1994), "Subjective Performance Measures in Optimal Incentive Contracts." Quarterly Journal of Economics, 109(4): 1125-1156.

[5] Bergstrom, T.C. (1999), "Systems of Benevolent Utility Functions." Journal of Public Economic Theory, 1(1): 71-100.

[6] Berman, E.M., J.P. West and M.N. Richter (2002), "Workplace Relations: Friendship Patterns and Consequences (According to Managers)." Public Administration Review, $62(2): 217-230$. 
[7] Brown, M., A. Falk and E. Fehr (2004), "Relational Contracts and the Nature of Market Interactions." Econometrica, 72(3): 747-780.

[8] Brown, M., A. Falk and E. Fehr (2012), "Competition and Relational Contracts: The Role of Unemployment as a Disciplinary Device." Journal of the European Economic Association, 10(4): 887-907.

[9] Bull, C. (1987), "The Existence of Self-Enforcing Implicit Contracts." Quarterly Journal of Economics, 102(1): 147-159.

[10] Campbell, C.M. and K.S. Kamlani (1997), "The Reasons for Wage Rigidity: Evidence From a Survey of Firms." Quarterly Journal of Economics, 112(3): 759-789.

[11] Carmichael, L. (1983), "The Agent-Agents Problem: Payment by Relative Output." Journal of Labor Economics 1(1): 50-65.

[12] Casadesus-Masanell, R. (2004), "Trust in Agency." Journal of Economics and Management Strategy, 13(3): 375-404.

[13] Cordero Salas, P. (2011), "The Role of Bargaining Power on Relational Contracts." SSRN Working Paper.

[14] Cordero Salas, P. and B. Roe (2012), "The Role of Cooperation and Reciprocity in Structuring Carbon Sequestration Contracts in Developing Countries." American Journal of Agricultural Economics, 94(2): 411-418.

[15] Delfgaauw, J. and R. Dur (2007), "Signaling and Screening of Worker's Motivation." Journal of Economic Behavior and Organization, 62(4): 605-624. 
[16] Dur, R. (2009), "Gift Exchange in the Workplace: Money or Attention?" Journal of the European Economic Association, 7(2-3), 550-560.

[17] Dur, R. and A. Glazer (2008), "Optimal Contracts When a Worker Envies His Boss." Journal of Law, Economics, and Organization, 24(1): 120-137.

[18] Dur, R. and J. Tichem (2012), "Social Relations and Relational Incentives." Tinbergen Institute Discussion Paper, TI 2012-054/1.

[19] Englmaier, F. and S. Leider (2012), "Contractual and Organizational Structure with Reciprocal Agents." American Economic Journal: Microeconomics, 4(2): 146-83.

[20] Gibbons, R. (1998), "Incentives in Organizations." Journal of Economic Perspectives, 12(4): 115-132.

[21] Gibbs, M. (2012), "Design and Implementation of Pay for Performance." Oxford Handbook in Managerial Economics, forthcoming.

[22] Gibbs, M., K.A. Merchant, W.A. Van der Stede, and M.E. Vargus (2004), "Determinants and Effects of Subjectivity in Incentives." The Accounting Review, 79(2): 409-436.

[23] Giebe, T., and O. Gürtler (2012), "Optimal Contracts for Lenient Supervisors." Journal of Economic Behavior and Organization, 81(2): 403-420.

[24] Grund, C. and D. Sliwka (2005), "Envy and Compassion in Tournaments." Journal of Economics and Management Strategy, 14(1): 187-207.

[25] Grund, C. and J. Przemeck (2012), "Subjective Performance Evaluation and Inequality Aversion." Applied Economics, 44(17): 2149-2155. 
[26] Kahneman, D., A.B. Krueger, D.A. Schkade, N. Schwarz, and A.A. Stone (2004), "A Survey Method for Characterizing Daily Life Experience: The Day Reconstruction Method." Science, 306(5702): 1776-1780.

[27] Kragl, J. and J. Schmid (2009), "The Impact of Envy on Relational Incentive Contracts." Journal of Economic Behavior and Organization, 72(2): 766-779.

[28] Lee, S. and P. Persson (2011), "Authority versus Loyalty: Social Incentives and Governance." NYU Working Paper, No. FIN-10-001.

[29] Levin, J. (2003), "Relational Incentive Contracts." American Economic Review, 97(3): $835-857$.

[30] MacLeod, W.B. and J.M. Malcomson (1989), "Implicit Contracts, Incentive Compatibility, and Involuntary Unemployment." Econometrica, 57(2): 447-480.

[31] MacLeod, W.B. and J.M. Malcomson (1998), "Motivation and Markets." American Economic Review, 88(3): 388-411.

[32] MacLeod, W.B. and D. Parent, (2000) "Job Characteristics and the Form of Compensation." Research in Labor Economics, 18: 177-242.

[33] Millward, N., M. Stevens, D. Smart, and W.R. Hawes (1992), Workplace Industrial Relations in Transition: The ED/ESRC/PSI/ACAS Surveys. Aldershot: Dartmouth.

[34] Moerbeek, H.H.S. and A. Need (2003), "Enemies at Work: Can They Hinder Your Career?" Social Networks, 25(1): 67-82. 
[35] Non, A. (2012), "Gift-Exchange, Incentives, and Heterogeneous Workers." Games and Economic Behavior, 75(1): 319-336.

[36] Prendergast, C. (1999), "The Provision of Incentives in Firms." Journal of Economic Literature, 37(1): 7-63.

[37] Prendergast, C. and R.H. Topel (1996), "Favoritism in Organizations." Journal of Political Economy, 104(5): 958-978.

[38] Raff, D.M.G., and L.H. Summers (1987), "Did Henry Ford Pay Efficiency Wages?" Journal of Labor Economics, 5(4): S57-S86.

[39] Rhoades, L. and R. Eisenberger (2002), "Perceived Organizational Support: A Review of the Literature." Journal of Applied Psychology, 87(4): 698-714.

[40] Shapiro, C. and J.E. Stiglitz (1984), "Equilibrium Unemployment as a Worker Discipline Device." American Economic Review, 74(3): 433-444.

[41] Shchetinin, O. (2010), "Altruism and Career Concerns." Gothenborg University, Working Papers in Economics 427.

[42] Sliwka, D. (2007), "Trust as a Signal of a Social Norm and the Hidden Costs of Incentive Schemes." American Economic Review, 97(3): 999-1012.

[43] Tichem, J. (2013), "Screening for Altruistic Supervisors." Mimeo, Tinbergen Institute.

[44] Wayne, S.J., L.M. Shore and R.C. Liden (1997), "Perceived Organizational Support and Leader-Member Exchange: A Social Exchange Perspective." Academy of Management Journal, 40(1): 82-111. 